\title{
Application of an Acid Extract of Barley Agro-Industrial Waste as a Corrosion Inhibitor for Stainless Steel AISI 304 in $\mathrm{H}_{2} \mathrm{SO}_{4}$
}

\author{
Larissa Aparecida Corrêa Matos ${ }^{1}$, Mariane Coussian Taborda ${ }^{1}$, Guilherme José Turcatel Alves ${ }^{1}$, \\ Maico Taras da Cunha ${ }^{1}$, Everson do Prado Banczek ${ }^{1}$, Marilei de Fátima Oliveira ${ }^{2}$, Eliane D'Elia', \\ Paulo Rogério Pinto Rodrigues ${ }^{1 *}$ \\ ${ }^{1}$ GPEL® Laboratório do Grupo de Pesquisas em Eletroquímica, Departamento de Química, \\ Universidade Estadual do Centro Oeste, Rua Simeão Camargo Varela de Sá 03, 85040-080, Vila Carli, \\ Guarapuava, Paraná, Brasil. \\ ${ }^{2}$ UTFPR, Avenida Professora Laura Pacheco Bastos 800, 85053-525, Industrial, Guarapuava, Paraná, \\ Brasil. \\ ${ }^{3}$ Departamento de Química Inorgânica, Instituto de Química, UFRJ, Avenida Athos da Silveira Ramos \\ 149, Centro de Tecnologia, Bloco A, Laboratório 634A, Cidade Universitária, Rio de Janeiro, 21941- \\ 909, Rio de Janeiro, Brasil. \\ *E-mail: prprodrigues@ unicentro.br
}

doi: $10.20964 / 2018.02 .01$

Received: 25 August 2017 / Accepted: 17 November 2017 / Published: 28 December 2017

Corrosion inhibitors are commonly used to reduce the effects of corrosive processes in metallic materials. However, many compounds are toxic and expensive and have negative effects on the environment. There is growing interest in replacing petroleum inhibitors with biodegradable inhibitors, such as plant extracts. Barley agro-industrial waste (AW) is a source of compounds with great inhibitor activity, and its use is desirable for minimizing the amount of AW. The aim of this paper is to demonstrate the application of an AW extract as a corrosion inhibitor for stainless steel AISI 304 in $\mathrm{H}_{2} \mathrm{SO}_{4}$. The efficiency of this acid extract was evaluated by weight loss measurements, scanning electron microscopy (SEM) analysis, open circuit potential (OCP) measurements, electrochemical impedance spectroscopy (EIS), and potentiodynamic polarization curves (PP). The proposed extract exhibited an inhibition efficiency of up to $97 \%$ and was physically adsorbed in the metallic surface. The SEM images indicated that the addition of the extract decreased metal oxidation. The electrochemical results for steel in the presence of the AW extract acted as a mixed-type inhibitor, likely changing the cathodic mechanism reaction on the uncovered surface. The AW extract can thus be used as an organic corrosion inhibitor.

Keywords: green inhibitor, sustainability, acid inhibition

\section{FULL TEXT}


(C) 2018 The Authors. Published by ESG (www.electrochemsci.org). This article is an open access article distributed under the terms and conditions of the Creative Commons Attribution license (http://creativecommons.org/licenses/by/4.0/). 